\title{
Inter district variation in child health promotion practices: A comparative study between the two districts in a South Indian state
}

\author{
B Shantharam Baliga1, Suchetha Rao', Animesh Jain ${ }^{3}$, K Nagaraj $^{4}$, BK Srikanth ${ }^{4}$ \\ ${ }^{1}$ Professor and Head, Department of Pediatrics, Kasturba Medical College, Mangalore (Affiliated to Manipal University), ${ }^{2}$ Associate Professor, \\ Department of Pediatrics, Kasturba Medical College, Mangalore (Affiliated to Manipal University), ${ }^{3}$ Professor and Head, Department of \\ Community Medicine Kasturba Medical College, Mangalore (Affiliated to Manipal University), ${ }^{4}$ Associate Professor, Department of Pediatrics, \\ Vijaya Nagar Institute of Medical Sciences, Bellary
}

\section{A B S T R A C T}

Background: Inter district variations in health parameters can be conducive for policy making with regards to child health status and healthcare utilization. Aims and Objectives: We carried out this study to understand district-wide variations in child health promotion practices in well performing Dakshina Kannada (DK) and poorly performing Bellary districts of Karnataka state of South India. Materials and Methods: Data was collected by cross sectional door to door community survey carried out among 2203 households of DK district and 2158 households of Bellary district. The Institutional Ethics Committee had approved this study. Result: Initiation of breast feeding within 2 hours was seen in $92.2 \%$ mothers in DK and $43.2 \%$ mothers in Bellary. Higher rates of prelacteal feeds (DK 16\% Bellary $68.1 \%$ ) and delayed complementary feeding (DK $39.2 \%$ Bellary 64.9\%) was observed in Bellary. Home deliveries were negligible in DK but in Bellary almost half of the mothers had delivered at home. Fever was recognized as danger sign in majority, while awareness of all danger signs was seen in $44.4 \%$ in DK and $14.8 \%$ in Bellary. $28 \%$ in Bellary had delayed health seeking. Conclusion: There is inter district variation child health promotional practices and health seeking and need due consideration by health policy makers.

Key words: Health care seeking, Danger signs, Child health promotion practices

\section{INTRODUCTION}

Health is an important component of human development. Access to proper health care is essential in improving health status. Inequalities related to socioeconomic status, geography and gender are the challenges to achieve quality of health care in India. ${ }^{1}$ High out-of-pocket expenditures also hinders quality of care. ${ }^{2,3}$ Wide heterogeneity in terms of various health indicators such as supply and demand sector are common. Supply sector represents the availability of health care services and demand side denotes access and accessibility of resources. Both the sectors being equally important, we can find out whether the role of government in these sectors is effective, efficient and equitable among the population group or there exist gap at various levels. There is a need for district- specific data for planning, improving quality of service and generating demand for health service utilization to improve child survival in India. ${ }^{4}$ We carried out a study to identify and understand district-wide variations in child health promotion practices with the following research objectives

- Is there a inter district variation in the health parameters?

- Is there a need to tailor the policies to the district as a unit?

\section{MATERIALS AND METHODS}

Prospective, community based study was carried out between November 2010 to May 2012 to compare the 
child health promotion practices between well performing district, Dakshina Kannada (DK) and poor performing district, Bellary of Karnataka State of South India. The DK district was ranked second in Karnataka state with a human development index (HDI) of 0.722 whereas Bellary district was ranked $18^{\text {th }}$ in the state with HDI of $0.617 .{ }^{5}$ The data was collected by community based door to door survey.

The districts were selected to represent different levels of health service systems, in terms of provisioning, performance and health indicators. Probability proportional to size (PPS) sampling technique was used to select the required number of clusters in each district. House hold with under five children were included. In households with more than one under five child, youngest child was included. The study was conducted after institutional ethics committee approval.

\section{Study instruments}

A team of pediatricians, nurses, medical social workers and biostatisticians conducted workshops to develop draft instruments. These were piloted for validity, question framing and relevance. Final instruments were prepared with the inputs from pilot study and then translated into local languages. The instruments included

(i) Household screening form to obtain information regarding socioeconomic status of the household and detailed obstetric history of women with under -5 children

(ii) Survey form to collect information regarding health promotional practices and care-seeking behavior among parents of under- 5 children.

\section{Data analysis}

The data was coded and analyzed using the SPSS package (SPSS Inc., Chicago, IL, USA, Ver 11.5). Results were expressed as rates. Outcome variables like antenatal care seeking behavior, place and person conducting the delivery, breast feeding and complementary feeding practices, awareness of danger signs of childhood illness and treatment seeking for childhood illness were compared in both the places. Independent sample ' $t$ ' test was used to compare means. A $\mathrm{p}$ value of $<0.005$ was considered as statistically significant.

\section{RESULTS}

After informed consent, 2203 households from DK and 2158 households from Bellary were enrolled for the study. On an average the households were composed of 6 members in DK and 7 members in Bellary. More nuclear families were found in DK in comparison to
Bellary. Child marriages were more common in Bellary $(24.8 \%)$ than DK $(11.5 \%)$ The age at first delivery $<18$ years was slightly higher in Bellary $(7 \%)$ than in DK $(4.2 \%)$ The age at first delivery $>25$ years was much higher in DK $(21.1 \%)$ when compared to Bellary $(5.9 \%)$. The birth order of 3 or more was higher in Bellary. The households in Bellary were poorer than DK consequently the larger number of surveyed households possess an Above the Poverty Line (APL) card in DK. Presence of health facility was at closer proximity in DK in comparison to that in Bellary. Table 1 depicts the socioeconomic status of the study population and distance of location of any health facility from their residence.

Most women from both districts had antenatal check-up (ANC) in our study population. However $16 \%$ did not have ANC at Bellary. Majority had ANC done by private doctor though this was slightly more in DK. Although at least one ANC scan was done in majority, more than 39\% of mothers in Bellary had not had even a single scan. Most of the deliveries in DK (97\%) were conducted by doctor or a health care professional, while almost half of the deliveries at Bellary were conducted by traditional birth attendants or dais (41\%). While majority of women in DK chose an institutional delivery, almost half of women in Bellary delivered at home. In DK majority of women chose a private hospital to deliver. Table 2 depicts the details of antenatal care seeking behavior and deliveries in both districts.

Initiation of breastfeeding was immediate or within two hours in majority at DK. However delay of 2 days and even more was reported at Bellary by more than 35\%. More than two thirds of infants in Bellary had been given

\begin{tabular}{|c|c|c|}
\hline Parameter & $\begin{array}{c}\text { DK } \\
\mathrm{n}=2202(\%)\end{array}$ & $\begin{array}{c}\text { Bellary } \\
\mathrm{n}=2158(\%)\end{array}$ \\
\hline \multicolumn{3}{|l|}{ Socioeconomic class } \\
\hline Upper (1) & $9(0.4)$ & $1(0.05)$ \\
\hline Upper middle (2) & $434(19.7)$ & $170(7.9)$ \\
\hline Middle lower middle (3) & $677(30.7)$ & $645(29.9)$ \\
\hline Lower upper lower (4) & $1074(48.8)$ & $1321(61.2)$ \\
\hline Lower (5) & $9(0.4)$ & $15(0.7)$ \\
\hline Unknown & & $6(0.25)$ \\
\hline Distance from house & & $p=<0.001$ \\
\hline to a health facility & & HS \\
\hline 1-2 kilometre & $911(41.4)$ & $871(40.4)$ \\
\hline 2-5 kilometres & $1218(55.3)$ & 481 (22.3) \\
\hline 5-10 kilometres & $69(3.1)$ & 467 (21.6) \\
\hline 10-20 kilometres & $5(0.2)$ & 330 (15.3) \\
\hline$>20$ kilometres & $0(0.0)$ & $9(0.4)$ \\
\hline
\end{tabular}


pre lacteal feeds compared to $16 \%$ at $\mathrm{DK}$. This practice is seen in a majority even among those delivered in the district hospital at Bellary. Exclusive breastfeeding of more than 6 months duration was seen in 30\% children at Bellary. Table 3 depicts the breast feeding and complementary feeding practices. With regards to immunization, both districts had a similar profile.

Awareness, knowledge and ability to recognize danger signs and symptoms in children are an important determinant of health care seeking. Only fever was the most well perceived

\begin{tabular}{lccc} 
Table 2: Antenatal care seeking and delivery \\
details of mothers with under five children \\
\hline Parameter & DK & Bellary & p value \\
& $\mathbf{n = 2 2 0 3}$ & $\mathbf{n = 2 1 5 8}$ & \\
& $\mathbf{( \% )}$ & $\mathbf{( \% )}$ & \\
\hline Antenatal check-up done & $2164(98.2)$ & $1804(83.6)$ & $<0.001 \mathrm{HS}$ \\
Antenatal check-up done by & & \multicolumn{2}{c}{$<0.001 \mathrm{HS}$} \\
Government doctor & $513(23.7)$ & $496(27.5)$ & \\
Private doctor & $1646(76)$ & $1101(61.0)$ & \\
Healthcare worker & $1(0.1)$ & $6(0.3)$ & \\
Nurse & $4(0.2)$ & $201(11.2)$ & \\
Place of delivery & & \multicolumn{2}{c}{$<0.001 \mathrm{HS}$} \\
Primary health care centre & $107(4.9)$ & $355(16.5)$ & \\
CHC/taluka hospital & $337(15.3)$ & $375(17.3)$ & \\
District maternity hospital & $294(13.3)$ & $137(6.3)$ & \\
Private hospital & $1400(63.5)$ & $273(12.7)$ & \\
Home & $65(3.0)$ & $1018(47.2)$ & \\
Person conducting delivery & \multicolumn{3}{c}{$<0.001 \mathrm{HS}$} \\
Doctor & $2114(96.0)$ & $716(33.2)$ & \\
Healthcare worker & $21(1.0)$ & $12(0.6)$ & \\
Nurse & $16(0.7)$ & $449(20.8)$ & \\
Dai & $14(0.6)$ & $891(41.3)$ & \\
Others & $38(1.7)$ & $90(4.1)$ & \\
\hline
\end{tabular}

\begin{tabular}{|c|c|c|c|}
\hline Parameter & $\begin{array}{c}\text { DK } \\
n=2203(\%)\end{array}$ & $\begin{array}{c}\text { Bellary } \\
\mathrm{n}=2158(\%)\end{array}$ & $p$ value \\
\hline $\begin{array}{l}\text { Initiation of breast } \\
\text { feeding }\end{array}$ & & & $<0.001$ \\
\hline Immediately & $1564(70.9)$ & $311(14.4)$ & \\
\hline $1-2$ hours & $467(21.3)$ & $618(28.7)$ & \\
\hline 2-24 hours & $132(6.0)$ & $437(20.2)$ & \\
\hline After 1 day & $40(1.8)$ & $792(36.7)$ & \\
\hline Pre lacteal feed & $360(16.3)$ & $1470(68.1)$ & $<0.001$ \\
\hline $\begin{array}{l}\text { Cessation of exclusive } \\
\text { breast feeding }\end{array}$ & & & $<0.001$ \\
\hline$<3$ months & 329 (14.9) & $140(6.5)$ & \\
\hline 4 months & 506 (22.9) & $187(8.7)$ & \\
\hline 5 months & $511(23.3)$ & $521(24.1)$ & \\
\hline 6 months & 724 (32.9) & $663(30.7)$ & \\
\hline$>6$ months & $133(6)$ & $647(30)$ & \\
\hline $\begin{array}{l}\text { Initiation of } \\
\text { complementary feeding }\end{array}$ & & & $<0.001$ \\
\hline$<3$ months & $65(3.1)$ & $26(1.4)$ & \\
\hline 4 months & $250(11.6)$ & $44(2.3)$ & \\
\hline 5 months & $487(22.6)$ & $146(7.8)$ & \\
\hline 6 months & $508(23.6)$ & $441(23.5)$ & \\
\hline$>6$ months & $844(39.1)$ & $1218(65)$ & \\
\hline
\end{tabular}

danger sign. The knowledge about all the six danger signs asked was present in less than half of the respondents in DK while in Bellary it was absolutely low at about $15 \%$. (Table 4)

All children in DK and almost $90 \%$ in Bellary had a health problem in the last one year with a frequency of 4-6 attacks in the year in a majority of them. Majority sought treatment within 1-2 days after the onset of symptoms. Delay in seeking treatment was seen in some households but this number was more than a quarter in Bellary where there was a delay of more than 3 days. (Table 4)

A health facility was present in the vicinity in most cases. Most of the times a travel of 2-5 $\mathrm{km}$ was needed to seek health care. In Bellary the accessibility of any health facility beyond $5 \mathrm{~km}$ was for $36.9 \%$ of the population and beyond $10 \mathrm{~km}$ was for $15.9 \%$ total population. This lack of access or long distance should have a negative impact on health seeking, however this trend was not seen as majority have sought health for their children in spite of distance.

\section{DISCUSSION}

Under five mortality (U5M) is a major public health challenge. Identifying determinants of U5M will assist in formulating appropriate health programs and policies in order to meet the millennium development goals. ${ }^{6}$ Uniform health policies are being implemented across the state or country. But these policies may not address the needs of the community as there are inter-district variations in the health indicators. ${ }^{4}$ Child survival interventions are not reaching the children who need them most. ${ }^{7}$ There are limited data on inter district variations in child health status and health services utilization within the states of India. This study was carried out to compare the child health promotional practices in well performing and poor performing districts of a state from South India.

Antenatal care seeking is an important determinant of neonatal health. ${ }^{8}$ Most women had ANC in our study. Shifting place of delivery from home to hospital is a key strategy for improving child birth outcomes and has led to unprecedented increases in institutional births in several countries. In DK, home deliveries were negligible but in Bellary, almost half of women had delivered at home. Non-utilization of health facilities for delivery, calls for a relook at the availability, affordability, and quality of services at these facilities. ${ }^{9}$ Continuous improvement in the skills and the quality of the village midwives might 


\begin{tabular}{lccc}
\multicolumn{3}{l}{$\begin{array}{l}\text { Table 4: Awareness of danger signs of childhood } \\
\text { illness and health care seeking behavior }\end{array}$} \\
\hline Parameter & DK & Bellary & p value \\
& $\mathbf{n = 2 2 0 3}(\%)$ & $\mathbf{n = 2 1 5 8}(\%)$ & \\
\hline Awareness of danger & & & \\
signs of childhood illness & & & \\
Not sucking properly & $960(43.6)$ & $346(16.0)$ & $<0.001 \mathrm{HS}$ \\
Fever & $2162(98.1)$ & $2103(97.5)$ & $0.04 \mathrm{~S}$ \\
Breathlessness & $1380(62.6)$ & $551(25.5)$ & $<0.001 \mathrm{HS}$ \\
Loose stools & $1317(59.8)$ & $1217(56.4)$ & $0.002 \mathrm{HS}$ \\
Blood in urine or stools & $1012(45.9)$ & $509(23.6)$ & $<0.001 \mathrm{HS}$ \\
Not taking food properly & $1052(47.8)$ & $379(17.6)$ & $<0.001 \mathrm{HS}$ \\
All of the above & $979(44.4)$ & $319(14.8)$ & $<0.001 \mathrm{HS}$ \\
Treatment seeking & & & $<0.001 \mathrm{HS}$ \\
Immediately & $158(7.2)$ & $171(9.0)$ & \\
Within 1 day & $590(26.8)$ & $640(33.0)$ & \\
In 2 days & $1227(55.7)$ & $557(28.6)$ & \\
$>3$ days later & $228(10.3)$ & $533(27.5)$ & \\
None & & $37(1.9)$ & \\
\hline
\end{tabular}

benefit maternal and newborn survival. ${ }^{10}$ In 2009, WHO and UNICEF issued a joint statement about home visits as a strategy to improve newborn survival on the basis of promising evidence from trials in south Asia. In the Newhints trial, this home-visits strategy reduced the neonatal mortality by $12 \%$ in sub-Saharan Africa. ${ }^{11}$ In Bellary district with high home deliveries such interventions may benefit in improving neonatal survival. Promotion of early initiation of breastfeeding has a significant role towards the achievement of the child survival millennium development goal; $16 \%$ of neonatal deaths could be saved if all infants were breastfed from day 1 and $22 \%$ if breastfeeding started within the first hour. ${ }^{12}$ Delayed initiation of breastfeeding has been associated with increased neonatal mortality. ${ }^{13}$ Early initiation as well as exclusive breastfeeding should be the goal of breastfeedingpromotion programs. In the well performing district early initiation of breast feeding and lesser use of pre lacteal feeds were seen.

Awareness, knowledge and ability to recognize danger signs and symptoms in children are an important determinant of health care seeking. If the parents do not consider the illness to be serious and miss the danger signs, they would neglect the health seeking by not considering it a priority. In general awareness of danger signs was relatively better in DK district. There is a need for retention of knowledge and convergence of peripheral health care providers. Delay in seeking treatment was seen in some households but this number was more than a quarter in Bellary where there was a delay of more than 3 days. This could be of concern as the delay could result in complications, mortality, higher cost owing to delay in diagnosis and progression of disease. The delay could be related to poverty, ignorance, illiteracy among people and inaccessibility and/or unavailability of the health care facilities.

\section{CONCLUSIONS}

There is inter district variation child health promotional practices and health seeking which needs due consideration by health policy makers. Our study suggests the need for adopting health policies and health care delivery tailored to the needs of the district and initiation of health care delivery monitoring systems in poor performing districts.

\section{ACKNOWLEDGEMENTS}

Indian Council of Medical Research (ICMR) HSR division. The study was conducted by ICMR research grant.

\section{REFERENCES}

1. Govinda R and Mita C. Health Care Financing Reforms in India. http://www.nipfp.org.in/newweb/sites/default/files/wp_2012_100. pdf

2. Roger PW and Anupriya G. Cultural aspects of primary healthcare in India: A case-based analysis. Asia Pacific Family Medicine 2011; 10:8.

3. Balarajan $Y$, Selvaraj S and Subramanian SV. India: Towards Universal Health Coverage 4 Health care and equity in India. Lancet 2011: 377; 505-515.

4. Lahariya C, Dhawan J, Pandey RM, Chaturvedi S, Deshmukh V, Dasgupta R, et al. Inter district variations in child health status and health services utilization: Lessons for health sector priority setting and planning from a cross-sectional survey in rural India. Natl Med J India 2012; 25(3):137-141.

5. Human development in Karnataka available at http:// planningcommission.nic.in/plans/stateplan/sdr_pdf/ shdr_kar05.pdf.

6. Kayode GA, Adekanmbi VT and Uthman OA. Risk factors and a predictive model for under-five mortality in Nigeria: Evidence from Nigeria demographic and health survey. BMC Pregnancy Childbirth. 2012; 12:10. doi:10.1186/1471-2393-12-10.

7. Bryce J, el Arifeen S, Pariyo G, Lanata C, Gwatkin D and Habicht JP. Multi-Country Evaluation of $\mathrm{IMCl}$ Study Group. Reducing child mortality: Can public health deliver? Lancet 2003; 362 (9378):159-164.

8. Kamal SM. What is the association between maternal age and neonatal mortality? An analysis of the 2007 Bangladesh Demographic and Health Survey. Asia Pac J Public Health 2015; 27(2):NP1106-17.

9. Jain A, Baliga BS, Rao S, Veera Shankar M and Srikanth BK. Does institutional delivery help in improving infant and child health care practices and health promotion related parameters? A study from Bellary, Karnataka. BMC Proceedings 2012;6 (Suppl 5):O22.

10. Titaley CR, Dibley MJ and Roberts CL. Type of delivery attendant, place of delivery and risk of early neonatal mortality: Analyses of the 1994-2007 Indonesia Demographic and Health Surveys. Health Policy Plan 2012; 5: 405-416.

11. Kirkwood BR, Manu A, ten Asbroek $A H$, Soremekun $S$, Weobong B, Gyan T, et al. Effect of the Newhints home-visits intervention on neonatal mortality rate and care practices in Ghana: A cluster randomised controlled trial. Lancet 2013;381(9884):2184-2192.

12. Edmond KM, Kirkwood BR, Amenga-Etego S, Owusu-Agyei S 
and Hurt LS. Effect of early infant feeding practices on infectionspecific neonatal mortality: An investigation of the causal links with observational data from rural Ghana. Am J Clin Nutr 2007; 86(4):1126-1131.
13. Edmond $\mathrm{KM}$, Zandoh $\mathrm{C}$, Quigley MA, Amenga-Etego $\mathrm{S}$ Owusu-Agyei $S$ and Kirkwood BR. Delayed breastfeeding initiation increases risk of neonatal mortality. Pediatrics 2006; 117(3):e380-e386.

Authors Contribution:

BSB - Conceptualized and designed the study, training of field workers, data collection,manuscript preparation and critical revision of the manuscript:

SR - Training of field workers, collected data, literature review, prepared first draft of manuscript and critical revision of the manuscript; AJ - Training of field

workers, collected data,literature search, statistically analyzed and interpreted the manuscript; KN and BKS- Supervision of field workers, collected data and

review of study.

Source of Support: The study was conducted by Indian Council of Medical Research (ICMR) Research Grant, Conflict of Interest: None declared. 